\title{
O DEPOIMENTO ESPECIAL EM CASOS DE VIOLÊNCIA SEXUAL
}

\author{
SPECIAL STATEMENT IN SEXUAL VIOLENCE CASES
}

Adriane da Silva Garcel ${ }^{1}$

\section{RESUMO}

O objetivo do trabalho é investigar o depoimento especial de crianças e adolescentes vítimas, ou testemunhas, de violência, à luz da Lei $n^{0} 13.431 / 2017$. A problemática do trabalho reside em analisar a figura do depoimento como meio de prova, sob o prisma histórico e evolutivo do instituto, abordando as vantagens e desvantagens de sua aplicação no processo penal, particularmente, na resolução de casos de violência sexual. Para tanto, realizou-se pesquisa bibliográfica em obras, artigos científicos e textos legais, adotando-se o método dedutivo. Como principal contribuição da pesquisa observa-se a importância do depoimento especial que preserva a vítima e testemunha menor dos constrangimentos decorrentes da

\footnotetext{
${ }^{1}$ Advogada licenciada na OAB/PR. Mediadora Judicial. Possui graduação em Letras - com ênfase em Português e Inglês pelo Centro Universitário Campos de Andrade (2005) com licenciatura Plena e Graduação em Direito pela Universidade Tuiuti do Paraná (2012). É especialista em direito público aplicado pela Escola da Magistratura do Paraná. É especialista em direito do trabalho e previdenciário pela Escola da Magistratura do Trabalho da $9^{a}$ Região - Centro Universitário Unibrasil. Atualmente é cursista na Fundação Escola do Ministério Público do Estado do Paraná. Possui Certificação de Mediação Judicial com Parecer do CNJ desde 22 de fevereiro de 2019. E ocupa o cargo de Secretário de Gabinete da 2. Vice-Presidência do Tribunal de Justiça do Estado do Paraná, atuando no assessoramento do Órgão especial e no Conselho da Magistratura. É Mestranda na UNICURITIBA, no Programa de Mestrado em Direito Empresarial e Cidadania, sob orientação do Dr. Fernando Sérgio Moro.

${ }^{2}$ Em 2004 concluiu o estágio de pós doutorado, junto ao departamento de sociologia da Faculdade de Direito da Universidade Degli Studi di Roma "La Sapienza", em programa de vinculado ao Ministério da Educação - Capes. É professor, foi diretor geral e ex-supervisor pedagógico da Escola da Magistratura do Paraná sendo coordenador científico de cursos de formação inicial e continuado para Magistrados junto a Emap, Coordenador Regional da Escola Nacional da Magistratura (ENM). Pertence a Comissão Permanente de jurisprudência, Revista, Documentação e Biblioteca, foi Presidente da $8^{a}$ e da $3^{a}$ Câmara Civel. Ex-membro do Conselho Nacional de Política Criminal e Penitenciária e pertence ao Conselho editorial da revista do CNPCP. Compõe o Conselho editorial da Revista da Escola da Magistratura; e o Conselho editorial da Revista Bonijuris; é membro do Corpo Editorial da Revista Judiciária da Associação dos Magistrados do Paraná; membro do Corpo Editorial da Revista de Estudos Jurídicos e Sociais da UNIPAR; membro do Corpo Editorial da Revista da Universidade Estadual de Londrina; É parecerista ativo eventos do CONPEDI, avaliador da Revista Direito e Desenvolvimento da UNIPE ? Universidade de João Pessoa, e da Revista Jurídica do Ministério Público de Santa Catarina. Foi o primeiro juiz dos juizados especiais, desde o início, e primeiro juiz do juizado criminal. E integrou turmas recursais. Tem experiência na área de Direito, com ênfase em Direito Público, atuando principalmente nos seguintes temas: jurisdição e processo constitucional, criminalidade, cidadania, juizados especiais e direito processual. Síntese: Desembargador do Tribunal de Justiça do Paraná, $2^{\circ}$ Vice-Presidente, Membro de seu Órgão Especial e Presidente do NUPEMEC . Mestre e Doutor pela Universidade Federal do Paraná UFPR. Pós-doutor pela Faculdade de Direito da Universidade Degli Studi di Roma ?La Sapienza?. Com Estágio de Pós-doutorado em Portugal e Espanha. Professor de direito processual no curso de mestrado da Universidade Paranaense ? UNIPAR, na União Educacional de Cascavel (UNIVEL) e na Universidade Estadual de Londrina (UEL). Autor de livros e diversos artigos jurídicos publicados em revista nacionais e internacionais. Parecerista de artigos acadêmicos, palestrante e conferencista no Brasil e no Exterior.

${ }^{3}$ Assessora Jurídica no Ministério Público do Estado do Paraná. Bacharel em Direito pela Pontifícia Universidade Católica do Paraná (Conclusão de curso em 2014). Especialista em Direito Público pela Fundação Escola do Ministério Público do Estado do Paraná (Conclusão em maio de 2016). Especialista em Direito Público pela Escola da Magistratura do Estado do Paraná (Conclusão em junho de 2019) ORCID: https://orcid.org/0000-0002-8897$148 \mathrm{X}$
} 
inquirição judiciária, evitando a repetição da narrativa do fato e o, consequente, fenômeno da vitimização, além de evitar os efeitos danosos do tempo em relação à memória. Por fim, o exame conclui pela necessidade de avaliação constante e permanente por parte dos Tribunais da utilização da técnica, com aprofundamento do estudo sobre o tema.

Palavras-chave: Depoimento Especial. Oitiva. Criança. Adolescente. Violência sexual.

\section{ABSTRACT}

The objective of the work is to investigate the special testimony of child and adolescent victims, or violence, in the light of Law $\mathrm{n}^{\circ} 13.431$ / 2017. The problem of the work lies in analyzing a figure of the testimony as a means of proof, under the historical and evolutionary prism of institute, addressing the advantages and disadvantages of its application in criminal proceedings, particularly in there solution of cases of sexual violence. For that, bibliographical research was carried out on works, scientific articles and legal texts, adopting the deductive method. As the main contribution of there search, the importance of special testimony that preserves the victim and minorwitness of the constraints resulting from the judicial inquiry is observed, avoiding the repetition of the narrative of the fact and the consequent phenomenon of victimization, in addition to avoiding the harmful effects of time in relation to memory. Finally, the exam concludes by the need for constantand permanent assessment by the Courts of the use of the technique, with further study on the subject.

Keywords: Special Testimony. Auditory. Kid. Adolescent. Sexual Violence.

\section{INTRODUÇÃO}

$\mathrm{Na}$ seara do processo penal, busca-se, sempre que possível, a verdade mais próxima da história levada ao conhecimento do julgador.

A despeito disso, as restrições técnicas da polícia judiciária brasileira fizeram da prova processual um dos meios de prova mais utilizado para o convencimento do julgador (LOPES JR., 2020, p. 516).

Particularmente, nos crimes sexuais cometidos em locais ermos e sem testemunhas, a palavra da vítima ganha relevância, tornando-se imprescindível para que o julgador possa chegar à melhor solução para o caso concreto.

Entretanto, não raras vezes, a vítima pode mostrar resistência para conversar a respeito do ocorrido, por motivos particulares, especialmente, nos casos envolvendo criança, ou adolescente, vítima, ou testemunha, de violência.

Nestes casos, a inexistência de regramento específico para a oitiva acabava por colocar em dúvida o conteúdo do depoimento, o que acarretava a desqualificação dos ofendidos e, consequente, fragilização do conjunto probatório. 
À vista disso, a Lei $\mathrm{n}^{\circ}$ 13.431/17 criou o chamado Projeto "depoimento sem danos, que passou a regulamentar o depoimento especializado, feito por profissionais, psicólogo, ou assistente social, utilizado para os casos que envolvam vítimas crianças, ou adolescentes.

$\mathrm{O}$ intuito principal da novel legislação foi o de evitar o depoimentode crianças e adolescentes por repetidas vezes, diante da constatação de que a sistemática outrora adotada dava margem a um ciclo de revitimização.

Neste contexto, o presente estudo tem por objetivoanalisar o depoimento especial, partindo da investigação da evolução legislativa do instituto. Busca-se, ainda, aferiros requisitos legais para a sua implementação e verificar quais os tipos de violência perpetrados contra crianças e adolescentes que ensejam o emprego desse procedimento judicial, com ênfase na violência sexual. Apresenta-se, na sequência, um paralelo entre as vantagens e as críticas à técnica, partindo-se de um viés jurídico processual e de caráter multidisciplinar.

Para tanto, far-se-á uso do método lógico-dedutivo, tendo como fonte artigos, doutrinas e Códigos Comentados a respeito do tema.

\section{BREVES CONSIDERAÇÕES SOBRE A TEORIA DA PROVA NO PROCESSO PENAL}

Na seara do processo penal, busca-se, sempre que possível, alcançar uma verdade que possa evidenciar a real história da situação levada ao conhecimento do julgador. Essa verdade, entretanto, não é aquela obtida a qualquer preço, eis que deve ser, sempre, processualmente válida, pautada nos princípios do contraditório e ampla defesa, identidade física do juiz, não autoincriminação e liberdade das provas, sob pena de nulidade e incontornável inconstitucionalidade, por afronta ao artigo $5^{\circ}$, incisos LIV e LV, da Constituição Federal.

A regra geral alberga o direito da livre produção probatória, vedando-se apenasàquelas que atentem contra a moralidade e dignidade humana, não estando as partes atreladas às hipóteses previstas em lei. A prova, sob a ótica do princípio do contraditório, compreende os momentos da postulação, admissão, produção e valoração (LOPES, 2013).

Dentre as modalidades probatórias previstas em lei, elencadas nosarts. 158 a 250 do CPP, o exame de corpo de delito, voltado para a comprovação da materialidade de um delito que deixa vestígios, muitas vezes é feito de forma indireta, precisamente quando os vestígios materiais desaparecem. A utilidade dessa modalidade ganha importância em crimes de conotação 
sexualpraticados por longo período de tempo que inviabilizam a prova técnica direta pelo desaparecimento dos vestígios.

Nestas circunstâncias, a prova da materialidade é suprida por outras modalidades de prova, ganhando relevo a palavra da vítima, nos termos do art. 167 do CPP.

Ademais, ainda que o direito ao interrogatório seja um direito do acusado, lhe é garantido permanecer em silêncio, de modo que evite a produção de provas contra si.

Embora muitas vezes o acusado confesse a autoria delitiva, especialmente, na fase inquisitiva, mesmo quando corroborada à fase processual, a denominadarainha das provas não pode ser tida como absoluta. Sem exceção, nos termos do art. 197 do CPP, o valor da confissão deverá ser aferido, confrontando-se a confissão com as demais provas coligidas, de modo a mensurar a compatibilidade entre ambas.

Além disso, confissão não pode ser fruto de coação moral, ou física, podendo, ainda, ser divisível e retratável (art. 200, do CPC), sem prejuízo do livre convencimento do julgador, que, em todas as hipóteses, deverá atenuar a pena quando considerar a confissão, nos termos da Súmula 545 do STJ: "quando a confissão for utilizada para a formação do convencimento do julgador, o réu fará jus à atenuante prevista no art. 65 , III, d, do CP ”.

Por fim, em virtude de restrições técnicas da polícia judiciária brasileira, a prova testemunhal tornou-seum dos meios de prova mais utilizado para o convencimento do julgador (LOPES JR., 2020, p. 516).

Neste contexto, o artigo 202 do Código de Processo Penal traça que toda e qualquer pessoa poderá testemunhar, fazendo alusão a possibilidade de que qualquer pessoa natural testemunhe, independentemente de discriminações histórica, excetuadas as pessoas jurídicas e àquelas elencadas no rol do artigo 207 do CPP (LOPES JR., 2020, p. 517).

Por sua vez, a oitiva deverá seroral, reduzida a termo e colhida em juízo durante audiência de instrução e julgamento, oportunidade em que as testemunhas prestarão o compromisso de dizer a verdade, sob pena de falso testemunho, nos termos do art. 210 do CPP.

\subsection{O VALOR PROBATÓRIO DO DEPOIMENTO DA VÍTIMA NOS CRIMES DE VIOLÊNCIA SEXUAL}

Tanto a prova testemunhal como a oitiva do ofendido constituem meios probatórios autônomos.

Com relação ao depoimento da vítima, tanto na fase indiciária como na judicial, a vítima deverá ser inquirida, podendo o juiz determinar diligência de ofício (art. 201, do CPP). 
Por sua vez, a ausência da oitiva configura nulidade relativa, desde que a parte demonstre o efetivo prejuízo (art. 563, do CPP).

Diferentemente da testemunha, a vítima não presta compromisso legal de dizer a verdade e não responde pelo crime de falso testemunho, na medida em que presta declarações e não depoimento.

Como a vítima pode estar inteiramente envolvida com o fato em análise, acometida por diversas emoções que podem conduzi-la a erro de percepção sobre os fatos ocorridos e, inclusive, em decorrência de seu notório interesse na punição do agente, muitos doutrinadores atribuem um valor relativo ao depoimento, em detrimento das demais modalidades probatórias, principalmente, quando se trata de crime de violência contra as pessoas.

Embora tais ressalvas, nos crimes sexuais, geralmente cometido às ocultas, em locais ermos e sem testemunhas, a palavra da vítima ganha extrema relevância, particularmente quando prestada de forma convicta, firme e harmônica com os demais elementos dos autos, tornando-se imprescindível para que o julgador possa chegar à melhor solução para o caso concreto.

Nos casos envolvendo violência sexual infanto-juvenil, uma das mais graves formas de violência, especialmente, por muitas vezes acontecerem contextos que violam as regras sociais e papéis familiares, ou de amizades próximas, ou relações de hierarquia social, a prova pericial, realizada apenas com o enfoque no exame físico, sem uma abordagem do aspecto emocional, na grande parcela das vezes se revela insuficiente.

Neste contexto, o depoimento da vítima ganha importância. Contudo, não raras vezes, ela pode mostrar-se resistente para conversar a respeito do ocorrido, por motivos particulares, como vergonha, culpa, preservação do sentimento de pertencimento do grupo familiar, medo por coação do agressor, ou de familiares.

Ainda, em alguns casos, a dificuldade em comprovar a conduta delituosa reside no fato de as vítimas serem crianças, ou adolescentes, porquanto estão mais propensas a formulação de fantasias e a sofrerem manipulações por parte de terceiros interessados na condenação do agressor, o que pode leva-lasa prestar declarações falsas. Somado a isso, muitas vezes os depoimentos infantis acabam sendo mais voláteis, exigindo extremo cuidado na avaliação.

Para além, a inexistência de regramento específico para a oitiva das vítimas acabava colocando em dúvida o conteúdo do depoimento, resultando na desqualificação dos ofendidos e na, consequente, fragilização do conjunto probatório. Frequentemente, estas circunstâncias dão margemà impunidade e ao retorno das vítimas ao mesmo ambiente, com reincidência delitiva, além de retaliações de ordem física e psicológica. 
À vista disso, foi criado o Projeto "depoimento sem danos, com criação da Lei $\mathrm{n}^{\mathrm{o}}$ 13.431/17, que passou a regulamentar o chamado "depoimento sem danos".

Desde então, a condução dos depoimentos nos casos envolvendo vítimas crianças, ou adolescentes, passou a se dar de modo especializado por profissionais, psicólogos, ou assistente social, em sala especial.

\section{DISPOSIÇÕES NORMATIVAS QUE REGEM O DEPOIMENTO ESPECIAL}

A ideia de implementação do depoimento especial partiu de discussões realizadas em convenções e protocolos internacionais ratificados pelo Brasil e as normas previstas na legislação nacional.

A técnica do depoimento sem danos e, na sequência, do depoimento especial, teve grande influência da "Convenção Internacional sobre os Direitos da Criança", que foi adotada pela Resolução ${ }^{0}$ 44, da Assembleia Geral das Nações Unidas, de 1989, ratificada pelo Brasil em 24/9/90, com a promulgação do Decreto $n^{0}$ 99.710/90.

A norma se pauta na doutrina da proteção integral, aplicada no Brasil por intermédio da Constituição Federal, e impõe aos signatários uma política de priorizaçãodos direitos básicos e especiais das crianças e dos adolescentes, como forma de proteção da infância, abrangendo a formação do caráter, da personalidade humana e da prevalência do seu maior interesse.

A Convenção representa um consenso de que existem alguns direitos básicos, universalmente implícitos, que são essenciais ao desenvolvimento completo e harmonioso de uma criança, representando o instrumento jurídico internacional mais completo para a promoção e o exercício do Direito da Criança (PEREIRA, 1992).

Dentre as prerrogativas da criança, a convenção incluiu o direito à participação, com salvaguarda da opinião, expressão das ideias e de sentimentos em situações de seu interesse, nos termos do art. 12 da Convenção Internacional sobre Direitos das Crianças (Decreto $\mathrm{n}^{\circ}$ 99.170/90).

Em qualquer processo envolvendo criança, administrativo, ou judicial, as autoridades têm obrigação de informá-la a respeito do procedimento por meio do qual será ouvida e das consequências da oitiva, seguindo-se à escuta da própria vítima, ou de seu representante, a respeito dos fatos retratados, de suas emoções e ideias. 
Uma vez realizada a escuta de maneira firme e consistente, as declarações devem ser consideradas pelo julgador como meio de prova, por ser um direito intrínseco da vítima, como sujeito de direito na ordem jurídica, que deve ser contraposto às demais provas.

Em verdade, a normatização do procedimento veio para romper com o estigma de que a palavra da criança não possui valor probatório, ou deve ser vista com ressalvas, conferindo legitimidade e capacidade para que fale por si, em defesa de seus próprios interesses, sendo suas opiniões mensuradas pelo julgador quando da sentença.

O direito da criança em prestar depoimento não impõe limitações em relação à idade biológica do infante. Sua capacidade deverá ser avaliada pelo julgadora partir da situação concreta, considerando o ambiente familiar em que vive, o nível de informação e o apoio recebido. Ainda, deve-se observar que o direito ao depoimento tem que ser realizado de forma profissional e acolhedora, de modo a não acarretar prejuízos à vítima.

Além do mais, a Resolução $n^{\circ}$ 20/2005, do Conselho Econômico e Social das Nações Unidas,contribuiu para a implementação do depoimento especial, por intermédio da Lei $\mathrm{n}^{\mathrm{o}}$ 13.413/17, estabelecendo orientações à Justiça, com destaque para a necessidade de dar-se garantia ao direito à sua participação em processo criminal.

A Resolução enfatiza a salvaguarda da justiça às crianças, sem prejuízo aos direitos dos acusados, destacandoa situação de vulnerabilidade que enseja a necessidade de proteção, assistência e apoio adequados à idade da criança, nível de maturidade e necessidades especiais. A normativa busca incentivar o compromisso dos países-membros na instauração de processos eficazes no combate à violência sexual contra crianças e adolescentes, no intuito de promover a escuta humanizada e implementar melhorias na qualidade do atendimento e identificação de casos de vitimização que requeiram o auxílio de prestação jurisdicional.

No âmbito nacional, a Constituição Federal de 1988, em seu artigo 227, caput e $\S 4^{\circ}$, antecedeu à Convenção Internacional sobre os Direitos da Criança, prevendo expressamente o dever da família, sociedade e Estado de assegurar à criança, adolescentes e jovens, com absoluta prioridade, o direito de estarem a salvo de violência, crueldade e opressão, além de punição legal em casos de abuso, violência e exploração sexual.

A doutrina da proteção integral, pautada nosprincípios da absoluta prioridade, melhor interesse da criança e da não discriminação, foi adotada pela Convenção sobre Direitos da Criança e pelo Estatuto da Criança e do Adolescente (Lei $n^{\circ}$ 8.069/90), um divisor de águas ao chancelar o entendimento de que crianças e adolescentes são sujeitos de direito e, portanto, titulares de direitos fundamentais, tal como qualquer outro ser humano. 
Nesta perspectiva, abandonou-se a antiga dicotomia entre menor e criança que, por corolário, passaram a ser sujeito de direitos e titulares de direitos fundamentais, além de incluídos nos códigos legislativos.

O modelo de proteção integral adotado pela Constituição Federal de 1988 há de ser cumprido pela família, sociedade e Estado mediante políticas públicas prioritárias, dada sua condição de peculiar de desenvolvimentoem relação aos demais, buscando colocá-las a salvo de qualquer forma de descaso, discriminação e violência.

Neste contexto, o depoimento especial se apresenta enquanto mecanismo de prevenção e impedimento de comportamentos negativos, tais como, a violência sexual e intrafamiliar.

O Estatuto da Criança e do Adolescente (ECA), também passou a prever expressamente hipóteses de escuta de crianças e adolescentes.

Em casos de guarda ou adoção, o $\S 1^{\circ}$ do o art. 28do ECA prevê a oitiva, sempre que possível, por equipe multidisciplinar, respeitado o estágio de desenvolvimento e grau de compreensão sobre as implicações da medida, devendo a opinião da vítima ser devidamente considerada. Por seu turno, o art. 100, parágrafo único, inciso XII, do ECA, determina a oitiva obrigatória da criança e do adolescente na aplicação de medidas protetivas, em separado, ou na companhia dos pais, responsáveis, ou pessoa por si indicada, devendo sua opinião ser ponderada pela autoridade judiciária competente.

À vista disso, verifica-se que já havia um direcionamento no ordenamento legal brasileiro no sentido de respeitar as opiniões da criança e do adolescente em inquirição humanizada, na presença de equipe técnica, nosprocessos de seu interesse, como veio a regulamentar a Lei $\mathrm{n}^{\circ}$ 13/431/17 que traça os parâmetros do depoimento especial.

Conforme se infere do art. 201, $\S 4^{\circ}, 5^{\circ}$ e $6^{\circ}$, do CPP, a legislação processual penal passou a garantir ao ofendido um espaço reservado para a sua oitiva, facultando ao juiz, se necessário, o encaminhamento da vítima para atendimento multidisciplinar psicossocial, assistência jurídica e saúde, às custasdo próprio ofendido, ou do Estado. Ainda, incumbindo o julgadorde tomar as providências necessárias para preservação da intimidade, vida privada, honra e imagem da vítima, o que abrange a decretação do segredo de justiça em relação ao depoimento, com vistas a evitar sua exposição.

$\mathrm{O}$ art. 217 do CPP, que estabelece a possibilidade de as testemunhas serem ouvidas sem a presença do acusado, também se aplica às vítimas, em especial nos casos de violência, pois a inquirição feita na presença do réu em audiência poderá causar temor, insegurança, humilhação ou intimidação da vítima. 
Por fim, osarts. 156, inciso I, e 225 do CPP, ao disporem sobre a produção antecipada de provas urgentes, antes de iniciada a ação penal, também se aplicam à oitiva de crianças e adolescentes na condição de vítimas, com o fim de protegê-las de inúmeras inquirições durante o processo, evitar a revitimização e minimizar a chance de esquecimento dos fatos, ou contradições, nas declarações, em razão do decurso do tempo.

\section{PROJETO DEPOIMENTO SEM DANO}

O arcabouço legislativo delineado ainda era omisso quanto ao procedimento da inquirição e proteção de vítimas e testemunhas infanto-juvenil nos casos praticados mediante violência, inclusive, sexual.

A oitiva era feita perante o juiz e as partes, sem a devida preparação por pessoas capacitadas. Em consequência, era comum a repetição dos detalhes do abuso com avitimização secundária, uma nova forma de violência, provocada pela própria sistemática adotada.

No sistema tradicional de depoimento, a criança, ou adolescente, eram indagado sem salas de audiência diretamente pelas partes e magistrado, o que gerava um ambiente de pressão que poderia levar a vítima à confirmação de fatos que não ocorreram, como uma forma de lhe atribuir falsas memórias.

Outra problemática decorria da presença, durante o depoimento, dos genitores, responsáveis, ou do próprio agressor, que desencadeava nova vitimização e, muitas vezes, contribuía para a insegurança do magistrado em condenar um suposto agressor, com base na palavra da vítima, sobretudo, quando era a única prova no processo, gerando baixos índices de condenação.

Em 2003, diante da necessidade de se estabelecer critérios mais rigorosos, foi elaborado o “Projeto Depoimento Sem Dano", criado pelo magistrado José Antônio Daltóe Cézar, do $2^{\circ}$ Juizado da Infância e Juventude de Porto Alegre/RS, a partir do trabalho monográfico apresentado pela Promotora Veleda Dobke, intitulado "Abuso Sexual: a inquirição das crianças - uma abordagem disciplinar".

O projeto formulou as diretrizes para a realização do depoimento sem danos, procedimento especial em que a criança, ou adolescente, fica numa sala reservada para colheita do depoimento por um técnico, psicólogo, ou assistente social, que faz perguntas de forma indireta, por meio de uma conversa em tom mais informal e gradual, à medida em que se procura estabelecer uma relação de confiança. 
O objetivo do projeto almejava não apenas a melhoria na produção da prova produzida, mas também a redução do dano na colheita de provas em processos judiciais, com o escopo de prevenir violações aos direitos das crianças e adolescentes, lhes conferir efetividade e proteção, respeitando a condição de pessoas em desenvolvimento.

No depoimento sem danos, a criança, ou adolescente, tinham contato particular com o profissional designado para a oitiva, em ambiente diverso da sala de audiências, mais receptivo e lúdico, com brinquedos, almofadas e material de desenho, possibilitando o relato de forma calma, em seu próprio ritmo e, principalmente, sem constrangimentos e pressões.

O estabelecimento de um local específico para a oitiva tem por objetivo facilitar a recuperação de fatos guardados na memória, o que é favorecido com a criação de um ambiente acolhedor (ROVINSKI; STEIN,2009, p. 316).

Além do mais, a escuta é acompanhada pelo Juiz, Ministério Público, réu e advogado, ou defensor público, em tempo real, em outra sala, por sistema audiovisual que grava a conversa do técnico com a vítima, permitindo que, no momento oportuno, possam formular perguntas para o esclarecimento dos fatos. Finda a inquirição, o depoimento é gravado em mídia e anexado ao processo, como elemento de prova.

Ainda que não obrigatório, o projeto piloto foi seguido pelo Poder Judiciário de outros estados da federação e passou a ser recomendado pelo Conselho Nacional de Justiça.

\section{O DEPOIMENTO ESPECIAL DA RESOLUÇÃO $\mathbf{N}^{\circ}$ 33/2010 DO CONSELHO NACIONAL DE JUSTIÇA}

A partir dos resultados obtidos com o "projeto depoimento sem danos", a Resolução $\mathrm{n}^{\mathrm{o}}$ 33/2010 do Conselho Nacional de Justiça passou a recomendar aos tribunais a criação de serviços especializados para a escuta de crianças e adolescentes vítimas, ou testemunhas, de violência nos processos judiciais, para garantir maior confiabilidade e qualidade.

O depoimento especial, regulamentado pelo $\mathrm{CNJ}$, consiste em um depoimento vídeogravado em ambiente separado da sala de audiências e devidamente preparado, com foco no conforto e acolhimento, onde profissional capacitado para realizar escuta deve estabelecer uma entrevista cognitiva. Essa técnica abrange: o dever de informação à criança e ao adolescente sobre o motivo da participação no processo; a prestação de serviços técnicos e apoio; orientação e encaminhamento das vítimas, ou testemunhas, e seus familiares, quando necessários, durante e após o procedimento judicial; ea adoção de medidas com o fim de conferir celeridade processual, 
reduzindo o tempo decorrido entre o conhecimento dos fatos e a audiência com a inquirição da vítima.

Para dar cumprimento a essas recomendações, a ONG Childhood do Brasil, em parceria com ouras instituições do Poder Judiciário, tanto do Brasil como de outros países, promoveu cursos de qualificaçãopara capacitar magistrados, psicólogos, assistentes sociais e pedagogosque atuariam na colheita do depoimento especial, de modo a garantir efetividadeprocessual.

\section{O DEPOIMENTO ESPECIAL EM SITUAÇÕES DE VIOLÊNCIA SEXUAL SOB A ÉGIDE DA LEI No $13.431 / 17$}

Conforme disposto em seu art. $1^{\circ}$, a Lei da Escuta Protegida (Lei $n^{\circ} 13.431 / 17$ ) tem por escopo normatizar e organizar o sistema de garantia de direitos da criança eadolescente vítima, ou testemunha, de violência, nos termos do art. 227 da Constituição Federal, da Convenção sobre os Direitos da Criança, seus protocolos adicionais e da Resolução n²0/2005 do Conselho e Social das Nações Unidas, além de outros diplomas internacionais.

Em seus arts. $2^{\circ}$ e $3^{\circ}$, a lei fixa obrigatoriedade da aplicação de seus conceitos e diretrizes às crianças e adolescentes, vítimas, ou testemunhas, de violência, a quem é novamente reconhecida a qualificação de pessoa titular de direitos fundamentais, em condição peculiar de desenvolvimento, incumbindo ao Poder Público, em conjunto com a família e a sociedade, proteger integralmente e com absoluta prioridade contra qualquer forma de negligência, discriminação, exploração, violência, abuso, crueldade e opressão.

A Lei $n^{\circ} 13.431 / 17$ também amplia o rol de destinatários, facultando aplicação aos casos de vítimas e testemunhas de violência, entre 18 e 21 anos, conforme o art. $2^{\circ}$ do ECA.

Ao longo de seus quatro incisos, o art. $4^{\circ}$ elenca as formas de violência às quais crianças $\mathrm{e}$ adolescentes não podem ser submetidas: (a) a violência física, entendida como ofensa à integridade, ou saúde corporal, que lhe cause sofrimento físico; (b) a violência psicológica, que abrange qualquer conduta de discriminação, depreciação, ou desrespeito mediante ameaça, agressão verbal, constrangimentos como bullying e alienação parental, ou qualquer outra conduta que exponha a criança ou adolescente, direta, ou indiretamente, a crime violento contra membro de sua família, ou rede de apoio; (c) a violência sexual, entendida como qualquer conduta que gere constrangimento à criança, ou adolescente, a praticar, ou presenciar, conjunção carnal, ou outro ato libidinoso, expor o corpo em vídeo, ou foto, por meio eletrônico, ou não, em situação de abuso sexual, exploração sexual, ou tráfico de pessoas e (d) a violência institucional, que vem 
a ser aquela praticada por instituição pública, ou privada, que pode incluir a revitimização da criança e do adolescente.

Quanto aos direitos e garantias da criança e do adolescente, quando inquiridos em sede indiciária, ou judicial, merecem destaque as seguintes prerrogativas do art. $5^{\circ}$ : (a) o direito de serem ouvidas e expressarem seus desejos e opiniões, bem como o de permanecerem em silêncio (inciso VI); (b) direito de receber assistência qualificada jurídica e psicossocial especializada, que facilite sua participação e o resguarde contra comportamento inadequado adotado pelos demais órgãos atuantes do processo (inciso VII); (c) direito de ser resguardado e protegido de sofrimento, com direito a apoio, planejamento de sua participação, prioridade na tramitação do processo, celeridade processual, idoneidade do atendimento e limitação das intervenções (inciso VIII); (d) direito de ser assistido por profissional capacitado e conhecer os profissionais que participam dos procedimentos de escuta especializada e depoimento especial (inciso XI); (e) direito de ter as informações prestadas tratadas confidencialmente, sendo vedada a utilização, ou repasse, a terceiros das declarações feitas pela criança e adolescente vítima, salvo para fins de assistência à saúde e de persecução penal (inciso XIV).

Destaca-se, ainda, a previsão do art. $6^{\circ}$ que assegura o direito de pleitear, por meio de seu representante legal, medidas protetivas contra o autor da violência e a definição das formas de escuta protegida de crianças e adolescentes vítimas de violência, escuta especializada realizada antes da fase judicial (art. $7^{\circ}$ ) e o depoimento especial, procedimento de oitiva de criança, ou adolescente, vítima, ou testemunha, de violência, perante autoridade policial ou judiciária (art. $\left.8^{\circ}\right)$.

\subsection{O PROCEDIMENTO DO DEPOIMENTO ESPECIAL}

O procedimento a ser adotado no depoimento especial é regulamentado no art. $9^{\circ} \mathrm{e}$ seguintes da Lei $\mathrm{n}^{\circ} 3.431 / 17$.

Em termos gerais, caso a vítima, ou testemunha, assim o queirao depoimento será prestado na presença do juiz e das partes, (art. $12, \S 1^{\circ}$ ); porém, a regra geral é a de que seja efetuado por equipe multidisciplinar, formada por profissionais especializados, que podem ser psicólogos, assistentes sociais, pedagogos, entre ou outros, erealizado em local apropriado e acolhedor, com infraestrutura e espaço físico que garanta a privacidade (art. 10), como forma de tornar a oitiva menos constrangedora e mais propícia à resolução do caso concreto. 
O objetivo desse procedimento é propiciar um relato mais aprofundado e verossímil, principalmente em casos de violência sexual, permitindo que o depoente, no seu tempo e com linguagem própria, descreva de maneira reservada a situação de abuso sofrida.

É com esse enfoque que a Lei $\mathrm{n}^{0} 13.431 / 17$ assegura a livre narrativa do depoente sobre a situação de violência, ressalvada à hipótese de intervenção por profissional especializado mediante adoção de técnicas menos indutivas, como a entrevista cognitiva, quando houver necessidade.

A técnica da entrevista cognitiva, voltada à coleta de testemunho adulto e infantil, baseada em conhecimentos científicos sobre a cognição humana e a comunicação social, tem sido adotada em diversos países, com resultados ótimos de fidedignidade, com a coleta de maior número de informações, quando comparada com outros métodos de entrevistas.

A entrevista é realizada por etapas, inicia-se com o acolhimento da vítima, ou testemunha, por meio de técnica conhecida como rapport, por intermédio da qual a criança,ou adolescente, ao chegar ao Fórum, é imediatamente acolhida por profissionais especializados, evitando o contato com o suposto agressor.

A primeira etapa consiste na prestação de esclarecimentos e informação de seus direitos e dos procedimentos a serem adotados, com o planejamento de sua participação, sendo vedada a leitura da denúncia e de outras peças processuais (art. 12, I).

A segunda etapa compreende a colheita das declarações da vítima, momento em que a criança, ou adolescente, conduz a oitiva, relatando, a seu modo e com suas próprias expressões, os fatos ocorridos, incumbindo ao profissional responsável o papel de viabilizar e incentivar anarrativa. Nesta fase, a assistente social busca falar abertamente sobre detalhes dos abusos, podendo se utilizar bonecos e marionete para auxiliar, de forma a estimular que o depoente faça o mesmo, encorajando-o a falar.

A inquirição é realizada por áudio e vídeo (art. 12, VI) e transmitida em tempo real para a sala de audiência, onde estará juiz, partes e acusados, acompanhados de outros serventuários da Justiça, preservando-se o sigilo (art. 12, III e $\S 6^{\circ}$ ).

É importante que a oitiva se dêsem a presença do suposto agressor, que poderá até mesmo ser afastado da sala de audiência quando sua presença puder prejudicar o depoimento, ou colocar o depoente em risco $\left(\operatorname{art} .12, \S 3^{\circ}\right)$.

A importância da proteção das palavras do depoente é tamanha para a elucidação dos fatos que o legislador estabeleceu o dever de o magistrado tomar todas as medidas apropriadas para a preservação da intimidade e privacidade do depoente, sem prejuízo das medidas protetivas cabíveis, no caso de risco à vida, ou integridade física (at. $12, \S 2^{\circ}$ e $4^{\circ}$ ). 
Importa ressaltar, ainda, que o desejo do legislador foi o de garantir que, quando se tratar de depoimento especial, a criança, ou adolescente, deve ter contato apenas com o profissional qualificado, como forma de garantir a fidedignidade de seu depoimento.

Além disso, é facultado ao juiz, após o livre relato do depoente, avaliar a pertinência de perguntas complementares, após consultar o Ministério Público, a defesa e a assistência técnica, as quais, se deferidas, devem ser feitas em blocos, podendo ser adaptadas pelo profissional especializado para uma melhor compreensão da criança e do adolescente.

Como regra, a colheita do depoimento deverá se dar em uma única oportunidade para evitar a revitimização e, com isso, a prática de violência institucional (art. 11, caput).

Ainda que indireta, a preocupação do legislador se direciona ao resguardo da memória do depoente dos efeitos maléficos do transcurso do tempo e das sucessivas entrevistas, que podem ser prejudiciais ao testemunho, pois associados à incorporação de informações falsas nos relatos subsequentes (DI GESU, 2017, p. 250).

Por sua vez, a lei $13.431 / 17$ propõe que, quando o depoente possuir idade inferior a sete anos de idade e/ou em caso de violência sexual, o depoimento especial será produzido em sede de produção antecipada de provas.

Por fim, o profissional que realizar a escuta deve cientificar o depoente e a família dos procedimentos a serem realizados após a oitiva e, caso se verifique a necessidade de acompanhamento psicológico e, até mesmo a aplicação de medidas cautelares, tais diligências devem ser encaminhadas ao juízo.

Destarte, denota-se que a técnica do depoimento sem danos, hoje denominada depoimento especial, teve por objetivo introduzir mecanismos para uma escuta humanizada, trazendo maior efetividade aos direitos da criança e adolescente, especialmente, quanto ao direito de participação no processo.

\subsection{VANTAGENS E DESVANTAGENS DO DEPOIMENTO ESPECIAL}

As críticas voltadas ao depoimento especial abrangem óticas interdisciplinares que vão para além dos aspectos técnico-processuais e jurídicos.

O Conselho Federal de Psicologia, em nota técnica, posicionou-se de forma totalmente desfavorável à técnica da escuta judicial de crianças e adolescentes.

Aponta-se que, ainda que proposto em nome da proteção de menores vítimas, ou testemunhas, de violência, a técnica viola a dignidade do depoente e sua condição peculiar de pessoa em desenvolvimento, vez que o coloca na posição de objeto de prova dentro do processo 
penal, por ser preponderante na elucidação dos fatos. Ademais, a metodologia adotada coloca o profissional psicólogo na condição de coletor de provas e reprodutor de perguntas, o distanciando por completo de suas atribuições, impedindo que o depoente retrate o abuso sofrido de maneira espontânea e real, com expressão de sentimentos de raiva, choro, frustração, medo, além de obstar o sigilo profissional.

Por meio de nota técnica, o Conselho Federal de Serviços Sociais destaca a gravidade em se atribuira os assistentes sociais a função de agentes capacitados para realizar a oitiva, pois além do notório desvio de atribuições, voltadas à proteção e atendimento das necessidades vitais do menor, como acolhimento institucional, constata-se uma insuficiência e precariedade no Poder Judiciário de equipes multidisciplinares.

Apesar disso, tem-se que a atuação destes profissionais na colheita das declarações de crianças e adolescentes vítimas, ou testemunhas, de violência é imprescindível e não pode ser substituída por outros profissionais, uma vez que são eles que detêm conhecimento sobre as técnicas necessárias de conversação, e, especialmente, de escuta atenta à narrativa da vítima.

Destarte, a atuação do profissional especializado possibilita a descrição da situação prevista de forma menos traumática possível, bem como a atuação do Estado no sentido de evitar que o abuso se repita. A contribuição desses profissionais proporciona a observância do direito de participação da criança, além de facilitar a coleta de um depoimento fidedigno e crível, capaz de amparar uma condenação criminal.

Outra crítica que se faz ao depoimento especial diz respeito ao fato de não respeitar o real desejo do depoente, pois obriga a vítima, ou testemunha, a falar a respeito dos fatos, mesmo quando não o queira fazer. Fala-se aquina violação do direito ao silêncio, que ganha maiores conotações nas situações de violência sexual intrafamiliar, quando a vítima mantém vínculos parentais significativos com o suposto agressor. Nesse aspecto particular, pondera-se que a criança, por instinto de sobrevivência, fundamentalmente vinculada e leal aos genitores, certamente vivenciará um conflito de lealdade em uma situação em que, para permanecer leal a um dos pais, precisará ser desleal ao outro.

Quanto a essa crítica, importa considerar que, embora a lei não trate expressamente do direito que tem o depoente de permanecer silente quanto aos fatos investigados, isto não significa que não lhe seja assegurada tal prerrogativa que, inclusive, é constitucionalmente garantida.

Ora, se a lei prevê que a narrativa é livre, pressupõe-se que a vítima vá dizer o que pretende, sem qualquer intervenção profissional, que só está autorizada a se manifestar quando necessário, por meio de técnicas voltadas à elucidação dos fatos. Perguntas só são feitas ao depoente quando o magistrado julgar pertinentes e, se o depoente não quiser responder, sua 
vontade deverá ser respeitada, pois o escopo maior da lei é a proteção da criança e do adolescente, como sujeito em condição peculiar de desenvolvimento.

Do ponto de vista jurídico, pontua-se o privilégio dos direitos garantidos à vítima, em detrimento das garantias do acusado, que fica cerceado em seu direito ao contraditório direto, prestado na presença do juiz e das partes.

Como ressaltam os posicionamentos contrários, o fato de a técnica ter mudado de denominação denota a arrogância do antigo nome "depoimento sem danos", eis que pressupunha a ausência de dano mesmo antes de realizado o ato, reforçando o posicionamento de que a oitiva não pode equivaler a um espetáculo punitivo do bem. Ainda que de boa-fé e amparado na lógica de se estar auxiliando na punição dos agressores, as vítimas devem ser adequadamente assistidas pelo Estado. E, para tanto, o único mecanismo democrático é o devido processo penal, acolhendo-se as posições dos Conselhos Profissionais que apontam a existência de métodos menos ingênuos, como a entrevista cognitiva e laudos qualificados. (LOPES; ROSA, 2019).

As críticas residem, ainda, no fato de que o procedimento transfere à vítima a produção da provaque, facilmente, poderia ser substituída por perícias que indicariam a presença de marcas físicas e danos psicológicos. Ademais, não se pode desconsiderar a possibilidade de que o depoimento especial, quando realizado em detrimento de perícias feitas por profissionais capacitados, pode acarretarerros judiciários, principalmente pela sugestão e induzimento, como se estuda em falsas memórias.

A problemática das falsas memórias diz respeito à possibilidade de que determinadas técnicas acabem criando memórias nas vítimas que não correspondam à realidade vivida e que são construídas justamente a partir de uma narrativa introduzida pelo profissional terapêutico. Isso na medida em que, pela própria constituição das memórias, o sentido é construído sempre após os fatos, a partir de uma interpretação subjetiva.

A despeito dos posicionamentos contrários, as críticas não correspondem ao espírito da lei $\mathrm{n}^{\mathrm{o}}$ 13.431/17, que teve por escopo justamente minimizar nulidades e erros judiciários, permitindo, de uma maneira distante e virtual, a participação ativa de todos os sujeitos do processo na inquirição, o que não se mostra viável na elaboração de laudos e entrevistas cognitivas feitas na fase indiciária que dispensam contraditório obrigatório.

No método judicializado do depoimento pessoal, tanto a defesa como a acusação podem intervir com indagações à vítima, feitas por profissionais habilitados, dentro do que se pretende provar no processo, o que possibilita a obtenção de uma solução judicial favorável.

De qualquer forma, observados os princípios do contraditório, ampla defesa e livre produção de provas, bem como estando à pessoa acusada da prática delitiva representada por 
defensor, apta a se defender no curso do processo sem restrições, pode-se chegar às seguintes vantagens para os defensores do depoimento especial: (a) redução do número de entrevistas por parte de outros profissionais, evitando a revitimização; (b) registro rigoroso da entrevista; (c) documentação visual dos gestos e expressões faciais que acompanham a fala da criança e (d) registro visual e verbal que pode ser revisto muito tempo depois, por outros profissionais.

Ademais, há que se ponderar que o depoimento especial é um instrumento de humanização, porquanto evita a submissão do depoente por várias vezes no curso da ação penal, coibindo a revitimização, além de evitar condenações genéricas e injustas, proporcionando a produção de provas mais contundentes e eficazes à comprovação do ilícito.

A técnica do depoimento especial se revela como medida necessária e adequada para a preservação da condição do depoente, criança, ou adolescente, em desenvolvimento. Além do mais, a colheita antecipada do depoimento vem a serforma de prevenção de novos abusos, demonstrando o lado benéfico do procedimento.

A ressalva a ser feita caminha não no sentido de se evitar a técnica do depoimento especial, mas sim na necessidade de se priorizar um conjunto probatório que não se ampare exclusivamente na palavra da vítima.

\subsection{A IMPLEMENTAÇÃO DO DEPOIMENTO ESPECIAL NO PODER JUDICIÁRIO}

Em virtude da recomendação $n^{\circ} 33 / 2010$ do CNJ, o depoimento especial já era adotado em alguns Tribunais Pátrios, como é o caso dos Tribunais de Justiça do Rio Grande do Sul, pioneiro na adoção da técnica; de São Paulo, com projeto-piloto elaborado em São Caetano do Sul, Atibaia e Campinas; do Paraná, mediante convênio firmado com o Ministério Público, Secretaria da Segurança Pública, Administração Penitenciária do Paraná, Defensoria Pública e Ordem dos Advogados do Brasil, estabelecendo diretrizes para atuação dos órgãos na aplicação do depoimento especial.

Por sua vez, quandoa Lei $n^{0}$ 13.431/17 entrou em vigor, o depoimento especial já estava sendo aplicado em pelo menos 24 dos 27 Tribunais Estaduais, estando em fase de adaptação nos Tribunais do Estado de Alagoas, Rondônia e Tocantins. Entretanto, até os dias de hoje, somente se realiza nas capitais, devido à dificuldade de implantação do método nas comarcas do interior, principalmente pela necessidade de contratação de profissionais qualificados e de recursos para cobrir as despesas com a construção de salas lúdicas, com decoração infantil e aquisição de equipamentos para gravação e teleconferência. 
Por sua vez, a implementação do sistema é monitorada pelo CNJ que, por meio de viagens realizadas por seus servidores, mapeia e averigua a observância dos padrões mínimos de qualidade, respeitada a autonomia dos tribunais.

Dados levantados pelo Supremo Tribunal Federal indicam, ainda, que há um esforço dos Tribunais para aperfeiçoar e capacitar seus servidores para que realizem entrevistas forenses, mediante cursos à distância oferecidos pela ONG Childhood, cujo convênio com o CNJ foi prorrogado por mais dois anos, em novembro de 2011.

Em 25 de setembro de 2018, no âmbito do Estado do Paraná, a Assessoria de Supervisão dos Núcleos Regionais de Informática do Departamento de Tecnologia da Informação e Comunicação deu início à implementação de Salas de Audiência com gravação de áudio e vídeo, incluindo software de captura integrado ao sistema Projudi, para atender a todas as 161 Comarcas do TJPR. A medida visava dar cumprimento integral as disposições da Lei $\mathrm{n}^{\mathrm{o}}$ 13.431/2017, particularmente, ao art. $4^{\circ}$, inciso IV e art. $405, \S 1^{\circ}$, do CPP, uma vez que, até então, apenas 22 Comarcas eram equipadas para a realização de "Audiências de Menor Dano".

Igualmente, a Resolução no 228/2019 do TJPR passou a regulamentar a produção da prova oral por meio de videoconferência no âmbito do Poder Judiciário do Estado do Paraná, sendo mais uma inovação no intuito de facilitar a oitiva de testemunhas, com a colheita dos depoimentos e interrogatóriospor meio de sistema audiovisual.

\section{CONCLUSÃO}

Da exposição feita, constata-se a importância da técnica do depoimento sem danos, uma vez que, muitas das vezes, a palavra da vítima é o único meio de prova.

A regulamentação do procedimento vem a corroborar a ótica constitucional e legal do direito de participação da criança e do adolescente na tomada de decisões em processos de seu interesse, tornando-se mecanismo estatal contra todos os tipos de violência, especialmente a sexual.

Embora a técnica ainda encontre resistência no âmbito jurídico, tradicionalmente conservador, importa ressaltar que o procedimento tem por finalidade preservar a vítima e testemunha menor dos constrangimentos decorrentes da inquirição judiciária e da repetição da narrativa do fato em si. O objetivo é evitar o fenômeno da revitimização, ouvindo-se o depoente, como regra, em uma única oportunidade, por pessoa capacitada para adotar técnicas humanizadas, evitando-se os efeitos danosos do tempo em relação à memória. 


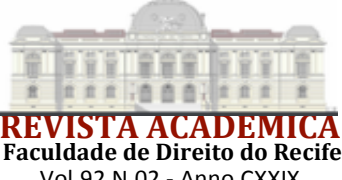

Faculdade de Direito do Recife

Vol.92 N.02 - Anno CXXIX

Diante do exposto, conclui-se que a técnica deve ser submetida aavaliação permanente por parte dos Tribunais, com constante aprofundamento de estudos sobre o tema, garantindo-se, dessa forma, sua eficiência para o processo penal, prestação jurisdicional e, principalmente, o respeito à proteção integral das crianças e adolescentes.

A dificuldade de julgamento de delitos desse jaez sempre exigirá do julgador a árdua tarefa de evitar o ciclo vicioso de perpetração da violência sexual contra menores, validando a palavra da vítima, mediante uma escuta atenta, mas sem cair no engodo de condenações dissociadas das prerrogativas constitucionais democráticas, especialmente as da presunção de inocência, do contraditório edevido processo legal.

\section{REFERÊNCIAS}

ARANTES, Esther Maria de Magalhães. Inquirição judicial de crianças: um debate necessário.Psicologia Clínica, Rio de Janeiro, v. 24, n. 1., p.45-56, 2012. Disponível em: http://www.scielo.br/pdf/pc/v24n1/04.pdf.Acesso em: 22 mar. 2019.

AZAMBUJA, Maria Regina Fayde. Violência sexual intrafamiliar: Interfaces com a convivência familiar, a oitiva da criança e a prova da materialidade. Revista dos Tribunais, São Paulo, v. 852, , p. 424-446, out. 2006.

BRASIL. Conselho Nacional de Justiça. CNJ analisa escuta judicial de crianças e adolescentes vítimas de violência. Conselho Nacional de Justiça, Brasília, 22 fev. 2019. Disponível em: https://www.cnj.jus.br/cnj-analisa-escuta-judicial-de-criancas-e-adolescentes-vitimas-deviolencia/. Acesso em: 17 abr. 2019.

BRASIL. Supremo Tribunal Federal. Presidente do STF prorroga cooperação do CNJ com a Childhood Brasil para enfrentamento da violência contra crianças. Brasília, 9 de nov. 2018. Disponível em: http://www.stf.jus.br/portal/cms/verNoticiaDetalhe.asp?idCont eudo=395235. Acesso em: 17 abr. 2019.

CEZAR, José AntonioDaltoé. Depoimento Sem Dano: uma alternativa para inquirir crianças e adolescentes nos processos judiciais. Porto Alegre: Livraria do Advogado, 2007.

CONSELHO FEDERAL DE PSICOLOGIA (Brasil). Nota técnica do CFP sobre os impactos da Lei $n^{0}$ 13.431/2017 na atuação das psicólogas e dos psicólogos.Conselho Federal de Psicologia. Brasília, 24 jan. 2017. Disponível em: http://www.crpsc.org.br/noticias/nota-t-cnica-do-cfpsobre-os-impactos-da-lei-n-13-431-2017-na-atua-o-das-psic-logas-e-dos-psic-logos.Acesso em: 01 abr. 2019.

DI GESU, Cristina. Prova Penal e Falsas Memórias.3.ed. rev.atual.. Porto Alegre: Livraria do Advogado, 2019.

DOBKE, Veleda. Abuso sexual: a inquirição das crianças: uma abordagem interdisciplinar.

Porto Alegre: Ricardo Lenz, 2001. 
FERNANDES, Antônio Scarance. O papel da vítima no processo criminal. São Paulo:

Malheiros, 1995.

LOPES, A.J.; ROSA, A.M.D.R. Depoimento Especial é antiético e pode levar a erros judiciais. Consultor jurídico,São Paulo, 23 jan. 2015.Disponível em:

https://www.conjur.com.br/2015-jan-23/limite-penal-depoimento-especial-antietico-levar-errosjudiciais-.Acesso em: 3 abr.2019.

LOPES JR, Aury. Direito Processual Penal. 10.ed.São Paulo: Saraiva, 2013.

LOPES JR, Aury. Direito Processual Penal. 17. ed. São Paulo: Saraiva Educação, 2020.

.PARANÁ. Tribunal de Justiça do Estado do Paraná. Resolução 228/2019. Regulamenta a produção de prova oral por meio de videoconferência no âmbito do Poder Judiciário do Estado do Paraná. Curitiba, 24 de jun. 2019. Disponível em: https://www.tjpr.jus.br/legislacao-atosnormativos/-/atos/documento/4584352. Acesso em: 15 ago. 2019.

PEREIRA, Tânia da Silva (coord). A Convenção e o Estatuto: um ideal comum de proteção ao ser humano em vias de desenvolvimento. In:ESTATUTO da Criança e do Adolescente: estudos sociojurídicos. Rio de Janeiro:Renovar, 1992.

OVINSKI, Sonia Liane Reichert; STEIN, LilianMilnitsky.O uso da EntrevistaInvestigativa no Contexto da PsicologiaForense. In: ROVINSKI, Sonia Liane Reichert;

CRUZ, Roberto Moraes. PsicologiaJurídica: perspectivasteóricas e processos de intervenção. 1. ed. São Paulo: Vetor, 2009.

SANTOS, Samara Silva dos; DELL'AGLIO, Débora Dalbosco. Quando o silêncio é rompido: o processo de revelação e notificação de abuso sexual infantil. Psicologia \& Sociedade,.v.22, n. 2, p. 328-335, 2010.

SOUZA, José Guilherme de. Vitimologia e Violência nos crimes sexuais:Uma abordagem interdisciplinar. Porto Alegre: S. A. Fabris, 1998., p. 392.

SOUZA NETTO, José Laurindo. GUILHERME, Gustavo Calixto. Garcel, Adriane. O Desenvolvimento e a proteção integral da criança e do adolescente na prática: os projetos realizados pelo Tribunal de Justiça e pelo Ministério Público do Estado do Paraná. In: LIVRO ECA 30 anos:Obra Coletiva alusiva aos 30 anos do Estatuto da Criança e do Adolescente com 39 artigos selecionados. Editora D’Plácido. 2020.

ZAVATTARO, Mayra dos Santos. Depoimento especial: aspectos jurídicos e psicológicos de acordo com a Lei no 13.431/2017. Belo Horizonte: Editora D’Plácido, 2018. p. 241. 